\title{
Yüksek Gerilim Kablo Başlık Arızalarını Önlemede Kılıf Gerilimi Tahmin Yöntemlerinin Karşılaştırılması
}

\author{
Bahadır Akbal \\ Konya Teknik Üniversitesi, Mühendislik ve Doğa Bilimleri Fakültesi, Elektrik-Elektronik Mühendisliği Bölümü, Konya, Türkiye (ORCID 0000-0002-7319-1966)
}

( $1^{\text {st }}$ International Conference on Computer, Electrical and Electronic Sciences ICCEES 2020 - 8-10 Ekim 2020)

(DOI: 10.31590/ejosat.804772)

ATIF/REFERENCE: Akbal, B. (2020). Yüksek Gerilim Kablo Başlık Arızalarını Önlemede Kılıf Gerilimi Tahmin Yöntemlerinin Karşılaştırılması. Avrupa Bilim ve Teknoloji Dergisi, (Özel Sayı), 338-344.

\section{$\ddot{O} \mathbf{z}$}

Yüksek gerilim yeraltı kablolarının metal kılıflarında oluşan gerilimi sıfırlamak ve kablo arızalarını önlemek amacıyla IEEE 575-1988 standardında yer alan yöntemlerle kablo topraklaması yapılmaktadır. Fakat kablonun metal kılıfından akan akım, yük akımının harmonik içermesine ve dengesizlik durumuna göre kılıf akımı, akım harmonikleri ve sıfır bileşen akımlarını içerebilir. IEEE 5751988 standardında yer alan yöntemler ile yapılan topraklama, sıfır bileşen ve harmonik akımlarının neden olduğu kablo başlığı arızalarını önlemede yetersiz kalmaktadır. Bu yüzden Parçalı Çift Taraflı Topraklama (PÇT) yöntemi sıfır bileşen akımları ve akım harmonikleri kaynaklı arızaların önlenmesi için geliştirilmiştir. PÇT yöntemindeki optimum parametre değerlerinin belirlenmesi için kabloda oluşacak olan kılıf geriliminin de bilinmesi gereklidir. Bu yüzden kabloda oluşacak kılıf gerilimi için tahmin yöntemleri kullanılmaktadır. Bu çalışmada daha iyi bir topraklama yapabilmek için kılıf gerilimi tahmininde kullanılan yöntemlerin doğrulukları karşılaştırılmıştır. Tahmin yöntemleri için yapay sinir ağları, genetik algoritma ile yapılan melez yapay sinir ağı ve regresyon yöntemleri kullanılmış, optimizasyon yöntemi olarak da genetik algoritma kullanılmıştır. Çalışma sonunda genetik algoritma ile yapılan melez yapay sinir ağının doğruluğu yaklaşık olarak \%99 ile en yüksek orandadır. Dolayısıyla genetik algoritma ile yapılan melez yapay sinir ağının tahmin yöntemi olarak kullanıldı̆̆ topraklama daha güvenilir olacaktır.

Anahtar Kelimeler: Yüksek gerilim kablosu, kablo başlığı arızası, regresyon, yapay sinir ağı, optimizasyon.

\section{Comparison of Sheath Voltage Prediction Methods to Prevent High Voltage Cable Termination Faults}

\begin{abstract}
High voltage cable bonding is carried out by the methods in the IEEE 575-1988 standard in order to reset the voltage on the metal sheaths of high voltage underground cables and prevent cable failures. However, the current flowing through the metal sheath of the cable may include the sheath current, current harmonics and zero component currents according to the harmonics of the load current and the imbalance state. Bonding by the methods in the IEEE 575-1988 standard is insufficient to prevent cable head failures caused by zero component and harmonic currents. Therefore, the Sectional Solid Bonding (SSB) method has been developed to prevent failures caused by zero component currents and current harmonics. In order to determine the optimum parameter values in the SSB method, it is necessary to know the sheath voltage that will occur in the cable metallic sheath. Therefore, estimation methods are used for the sheath voltage. In this study, the accuracy of the methods used in the sheath voltage estimation is compared to make better grounding. For estimation methods, artificial neural networks, a hybrid artificial neural network with genetic algorithm and regression methods are used, and genetic algorithm is used as an optimization method. The accuracy of the hybrid neural network made with the genetic algorithm at the end of the study is approximately 99\%. Therefore, grounding with the parameters obtained in a SSB optimization using the hybrid artificial neural network made by the genetic algorithm will be more reliable.
\end{abstract}

Keywords: High voltage cable, cable termination fault, regression, artificial neural network, optimization. 


\section{Giriş}

Elektrik enerjisinin iletiminde ve dağıtımında havai hatlar ve yeraltı kablolu hatlar kullanılmaktadır. Havai hatların yalıtım sorunundan dolayı yerleşim birimlerine belli mesafelerde tesis edilirken, yeraltı kablolarının bir yalıtkan tabakaya sahip olmasından dolayı böyle bir mesafeye gerek yoktur [1]. Bu yüzden şehir merkezlerinde ve kalabalık yerleşim birimlerinde yüksek gerilimin dağıtılmasında yüksek gerilim kabloları kullanılmaktadır.

Yüksek gerilim yeraltı kablolarında yalıtkan olarak PVC (polivinil klorür) veya XLPE (çapraz bağlı polietilen) kullanılmaktadır. Yüksek gerilim yeraltı kablolarında elektrik alan dağılımını düzgünleştirmek ve yalıtkan tabakayı korumak amacıyla birçok tabaka bulunur. Şekil 1'de bir yüksek gerilim kablosunun tabakaları gösterilmektedir [2].

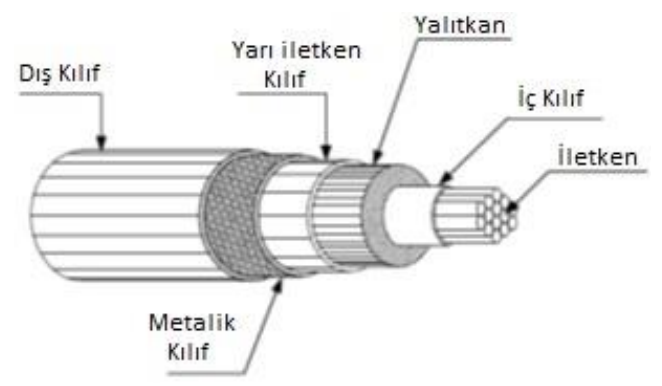

Şekil 1. Yüksek gerilim kablosu

Yüksek gerilim kablosunda enerji taşıma işlemi iletken ile yapılmaktadır. Kablonun tesis edildiği bölgede yüksek nem olabilir. Nem iletkende oksitlenmeye neden olur. Bundan dolayı da yalıtkan tabaka oksijen ile temas etmiş olur. Oksijen yalıtkanın ömrünün azalmasında dolayısıyla kablo arızalarında önemli etkenlerden birisidir. Bundan dolayı iletken üzerine genellikle PVC iç kılıf konulmaktadır. İç kılıf yalıtkan ile iletken arasında tabaka oluşturarak yalıtkanın oksitlenme sonucu ömrünün azalmasını önler. Yüksek gerilim kablolarında yalıtkan üzerindeki elektrik alan dağılımının düzgün olması gerekir. Bu yüzden yalıtkan tabakanın üzeri elektrik alanın düzgün dağılması için yarı iletken kılıf ile kaplanır [3]. Yarı iletken kılıfında metal bir kılıf ile kaplanması ile kablonun mekanik etkilere karşı korunması sağlanır.

Yeraltı kabloları iyi bir yalıtkan tabakaya sahip olduklarından yüksek gerilim tesislerinde yüksek gerilim elemanları arasındaki bağlantıları sağlamada da kullanılır. Bu bağlantı için de kablo başlıkları kullanılmaktadır. Kablo başlıkları bağlantı noktalarındaki atlamaların önlenmesinde kullanılır. Bağlantılar dış ortamda veya iç ortamda olabileceği için kablo başlıkları iç ortam (dâhili) ve dış ortam (harici) kablo başlıkları olarak üretilir. Dış ortam ve iç ortam kablo başlıkları Şekil 2'de gösterilmektedir.

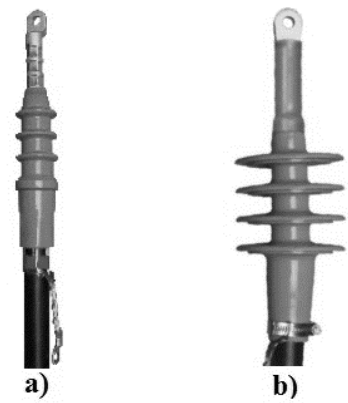

Şekil 2 a) İç ortam kablo başlı̆̆ b) Diş ortam kablo başlı̆̆

Yük akımının oluşturduğu manyetik alandan dolayı kablonun metal kılıfında gerilim endüklenir [4]. Kablo uzunluğunun artması ile de bu gerilimin değeri büyür [5]. Kablo üzerindeki potansiyeli sıfirlamak amaciyla yüksek gerilim kablosunun metal kılıfı topraklanır. Kablo topraklaması için IEEE 575-1988 standardında belirtilen yöntemler uygulanmaktadır [6]. Bu topraklama yöntemleri tek taraflı, çift taraflı ve çapraz topraklama yöntemleridir ve sıra ile Şekil 2, Şekil 3 ve Şekil 4'te gösterilmektedir.

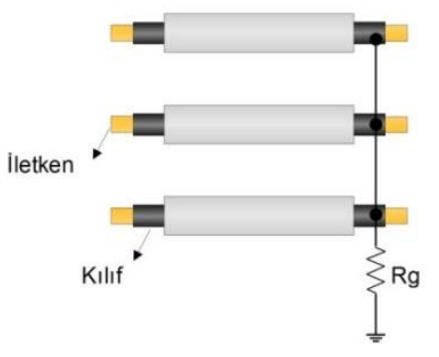

Şekil 2. Tek taraflı topraklama 


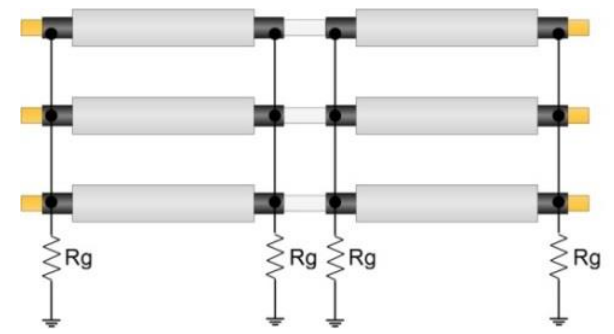

Şekil 3. Çift taraflı topraklama

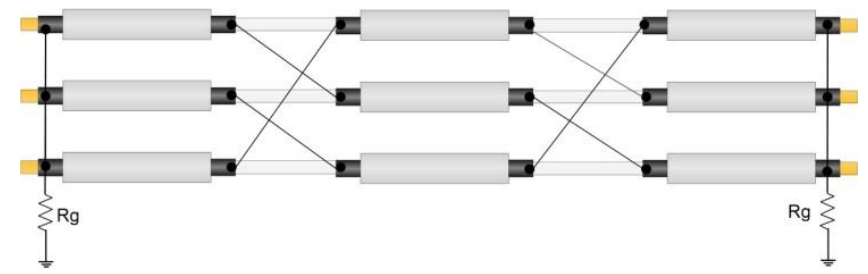

Şekil 4. Çapraz topraklama

Uygulamada genellikle kısa hatlarda tek taraflı topraklama, uzun hatlarda ise çift taraflı topraklama kullanılmaktadır.Kablo başlığı hat başı ve hat sonundaki ağlantılar için yapılmaktadır. Bu yüzden yüksek gerilim kabloları başlık noktalarından topraklanırlar. Kablo topraklandıktan sonra ise kılıf akımı akmaya başlar [7-9]. Yalıtkanın özelliğini çabuk yitirip delinmesine neden olan diğer önemli etken ise sıcaklıktır. Kılıf akımı yalıtkan üzerindeki sıcaklığı artırdığı için kablo arızalarına dene olmaktadır [10-12]. Eğer yük akımı harmonik içeriyorsa bu durumda kablo kılıfından akım harmonikleri de akacaktır. Akım harmonikleri bu sıcaklık artışını daha da yükselterek kablo arızalarında önemli rol almaktadırlar

Dağıtım hatlarındaki dengesizlikler sonucu güç trafolarının nötr noktasından sıfır bileşen akımları akar. Sıfır bileşen akımları da devrelerini kablonun metal kılıfından tamamlayarak yalıtkan üzerindeki sıcaklığın daha da yükselmesine neden olur. Bu durum Şekil 5 'te de gösterilmektedir. Dolayısıyla sıfır bileşen akımları da kablo sıcaklığını artırıcı etkenler arasında yer almaktadır [14,15].

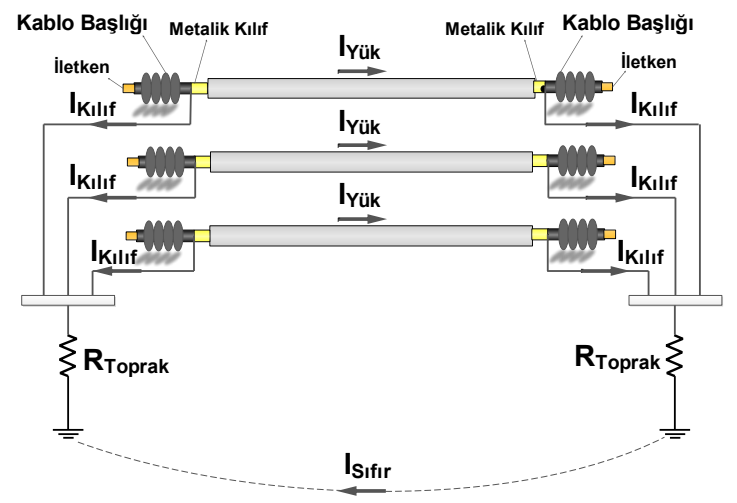

Şekil 5. Metlik k1lıf topraklama

Kablolarda gerilim ve sıcaklık artı̧̧ en fazla başlık bölgesinde olduğu için arızalar da genellikle başlık bölgesinde olmaktadır. Sıfır bileşen akımı ve akım harmoniklerinden dolayı oluşan kablo başlığı arızalarını önlemek amacıyla Parçalı Çift Taraflı (PÇT) topraklama yöntemi geliştirilmiştir [16].

\section{Materyal ve Metot}

Bu çalışmada yüksek gerilim yeraltı kablolu hatlarla ilgili çalışmalar PSCAD/EMTDC programında yapılmıştır. Çalışmada $36 \mathrm{kV}$ dağıtım hatlarında kullanılan XLPE yalıtkanlı yüksek gerilim kablosu kullanılmış ve bu kablo PSCAD/EMTDC programında modellenmiştir. Modellenen yüksek gerilim kablosu Şekil 6'da gösterilmektedir. 


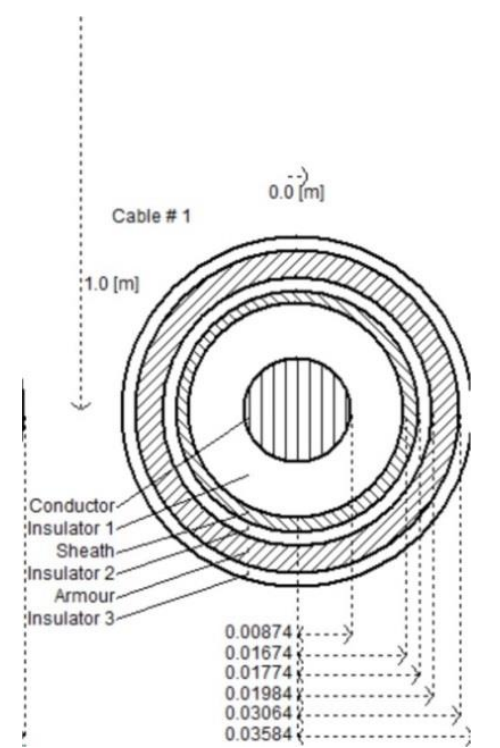

Şekil 6. Modellenen yüksek gerilim kablosu

Yüksek gerilim kablolarındaki arızaların önüne geçebilmek için iyi bir kablo topraklaması yapmak gerekir. İyi bir kablo topraklaması yapabilmek içinde kılıf gerilimine ve akımına etki eden etkenlerin iyi bilinmesi gerekir. Bu etkenlerin belirlenmesi için literatür araştırması ve benzetim çalışmaları yapılmıştır. Benzetim çalışmalarında birbirinden farklı birçok yeraltı kablolu hat oluşturulmuştur. Çalışmalar sonunda kılıf akımında dengesiz yük akımı, fazlar arası mesafe, toprak direnci, kablo tertibatı, topraklama yöntemi ve kablo uzunluğunun etkili olduğu görülmüştür.

Kablo metal kılıfı üzerindeki potansiyeli sıfırlamak için metal kılıf topraklanmaktadır ve uygulamada IEEE 575-1988 standardında belirtilen yöntemler uygulanmaktadır. Fakat sıfır bileşen akımları ve akım harmonikleri nedenli kablo başlığı arızaları IEEE 575-1988 standardına belirtilen yöntemler ile önlenemez. Çünkü bu yöntemler tasarlanırken akım harmonikleri ve sıfır bileşen akımı dikkate alınmamıştır. PÇT yöntemi sıfır bileşen akımları ve akım harmonikleri nedenli kablo başlığı arızalarını önleme amacıyla geliştirilmiştir. Bu yöntem Şekil 7’de gösterilmektedir.

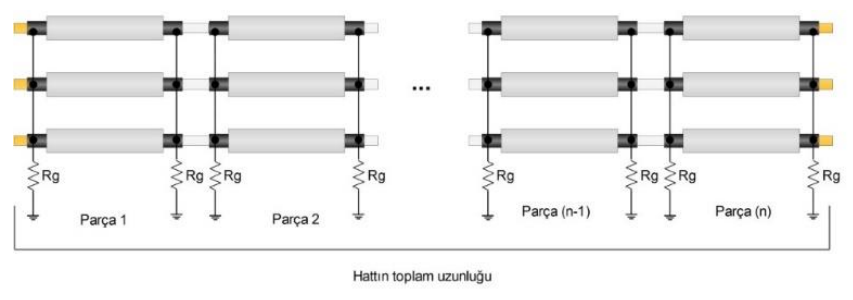

Şekil 7. Parçalı çift taraflı topraklama

PÇT yönteminde amaç güvenli ve ekonomik bir topraklama yapmaktır. Öncelikle güvenliği sağlamak için toplam hat uzunlu belirli uzunluklardaki hat parçalarına ayrılırlar. Bu hat parçalarının fazla olması fazla işçilik ve ek malzeme kullanımı gerektirecektir. Bu durum topraklamanın ekonomik olmayacağı anlamı taşır. Dolayısıyla istenen düzeyde güvenlik ve ekonomikliği sağlamak için PÇT yönteminin optimizasyonu gerekmektedir.

PÇT parametrelerinin optimizasyonu metal kılıf üzerinde oluşan gerilime göre yapılmaktadır. Uygulamada genellikle kablo topraklamasının uygunluğu hat devreye alındıktan sonra gözden geçirilir. Eğer bir arıza yoksa topraklamada değişiklik yapılmaz. Fakat önlenemez arızalar oluşursa topraklama için yeni alternatifler üretilir. Bu durum hem güvenlik hem de ekonomiklik yönünden uygun değildir. dolayısıyla bu çalışmada halen tesis edilmemiş bir yüksek gerilim yeraltı kablolu hat için PÇT yöntemi ile kablo topraklaması tasarlanmıştır. Kablo hattı daha tesis edilmediği için kılıf üzerindeki gerilim de bilinemez. Dolayısıyla bu çalışmada kılıf gerilimi tahmini için yapay siniz ağları, melez yapay sinir ağı ve regresyon yöntemlerinin doğruluk bakımından karşılaştırılması yapılmıştır. Bu tahmin yöntemleri oluşacak olan kılıf gerilimlerini tahmin ettiği için PÇT parametrelerinin optimizasyonunda bir amaç fonksiyonu olarak kullanılmaktadır.

Yapay sinir ağı (YSA) giriş, gizli ve çıkış katmanı olmak üzere 3 temel katmandan oluşur ve en temel elemanı nörondur [17,18]. Nöronlar gizli katmanda bulunur ve bir transfer fonksiyonu olarak görev yaparlar. Denklem (1)'de bir nöronun işleyişinin matematiksel ifadesi gösterilmektedir.

$$
y_{i}=f_{i}\left(\sum_{j=1}^{n} w_{i j} \times x_{j}+b_{i}\right)
$$

Burada $x_{j}$ giriş, $w_{i j}$ ă̆ırlık, $b_{i}$ bias, $f_{i}$ transfer fonksiyonu ve $y_{i}$ nöronun çıkışıdır.

YSA'da parametre tahminin yapılabilmesi için öncelikle bir eğitim süreci gereklidir ve eğitim sonunda YSA'nın eğitim hatası hesaplanır. YSA'da eğitim hatası en küçük kareler (Mean Square Error, MSE) yöntemi ile hesaplanmaktadır ve denklem (2)'de gösterilmektedir. 


$$
E(t)=\frac{1}{n} \sum_{i=1}^{n}(p(i)-o(i))^{2}
$$

Burada $E(t)$ hata, p(i) i. giriş için gerçek yani istenen çıkış değeri, o(i) i. giriş için tahmin edilen çıkış değeridir. Tahmin doğruluğunun yüksek olması için eğitimin hatasının minimum olması gerekir. Bu yüzden, YSA'nın ağırlıkları hatanın değerine göre güncellenir. En düşük hatayı veren ağırlıklar en iyi ağırlıklardır. Klasik YSA'da ağırlıkları güncellemek için denklem (3), denklem (4) ve denklem (5) kullanilır.

$$
\begin{aligned}
w_{i}(t+1) & =w_{i}(t)+\Delta w_{i}(t) \\
\Delta w_{i}(t) & =\eta \times e(t) \times n_{i}(t) \\
e(t) & =p(i)-o(i)
\end{aligned}
$$

Burada $\eta$ öğrenme katsayısıdır. Literatürde hatanın düşürülmesinde melez YSA yöntemleri kullanılmaktadır. Melez YSA yöntemlerinde ağırlıkların güncellenmesi için bulanık mantık ve optimizasyon yöntemleri kullanılmaktadır. Bulanık mantıkla yapılan çalışmalarda uzman görüşü ve kurallar gereklidir. Eğer uzman görüşü ve kurallar tam olarak belirlenemezse hassas sonuçlar elde edilemez. Optimizasyon yöntemlerinde ise uzman görüşüne ve kurallara gerek yoktur. Bu yüzden, hassas sonuç elde edilmesi daha kolaydır. Bu çalışmada da YSA'nın ağırlıklarının güncellenmesi için Genetik Algoritma optimizasyon yöntemi olarak kullanılmışır. Optimizasyon yöntemi ile yapılan melez YSA yönteminin algoritması Şekil 8'de gösterilmektedir.

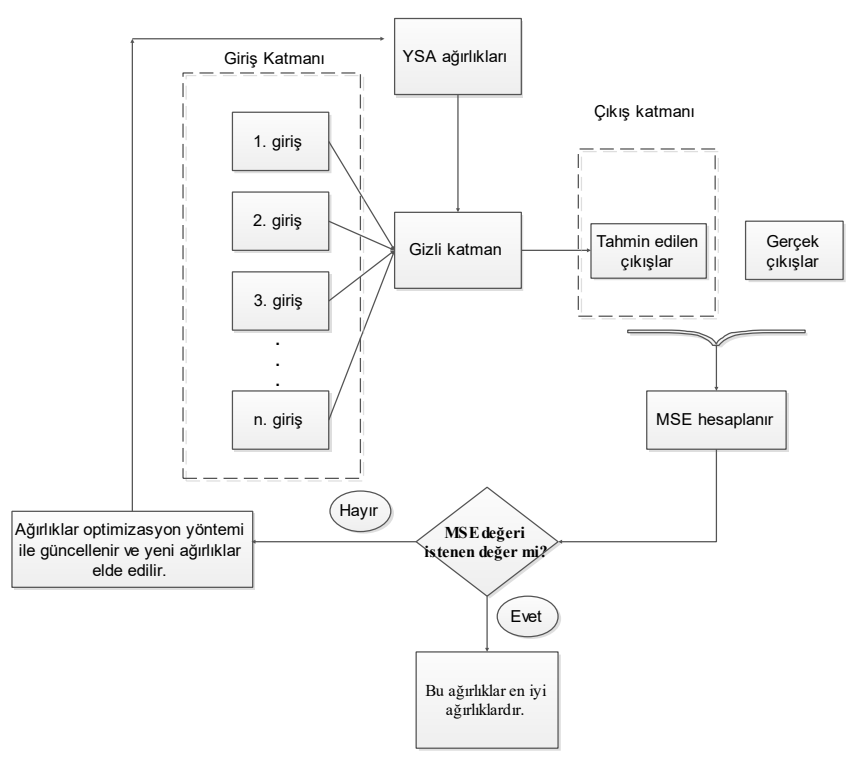

Şekil 8. Melez YSA algoritması

Diğer bir tahmin yöntemi ise regresyondur. Regresyonda bağımlı ve bağımsız değişskenler bulunmaktadır. Bu değişkenler arasındaki iliş̧iye göre bir denklem oluşturulur ve bu denklem ile tahmin işlemleri gerçekleştirilir. Bu denklem, denklem (6)'da gösterilmektedir [19].

$$
Y=a+b \cdot X
$$

Burada y bağımlı değişken, $\mathrm{X}$ bağımsız değişken, a ve b ise katsayılardır. Bağımlı değişekn genellikle çıkış verisi iken bağımsız değişkenler ise giriş verileridir.

$\mathrm{Bu}$ girişler ve çıkışlar arasında doğru veya ters ilişkiler bulunabilir. Eğer bir girişin değeri artarken çıkışın değeri de artıyorsa doğru orantılı bir iliş̧ki vardır denir. Eğer bir girişin değeri artarken çıkışın değeri azalıyorsa veya bu olayın tam tersi oluyorsa ters orantılı bir ilişki vardır denir. Bu girişler ile çıkışlar arasındaki ilişkiye göre bir denklem elde edilir ve buna göre parametre tahmini yapılmaktadır. Bu ilişkiler Şekil 9'da gösterilmektedir. 

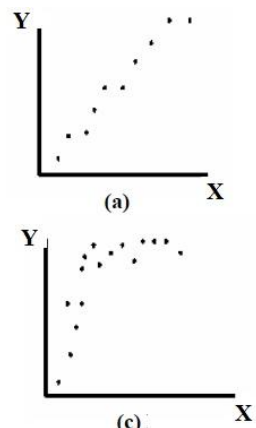

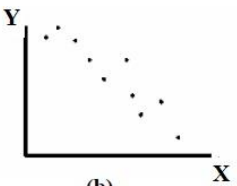

(b)

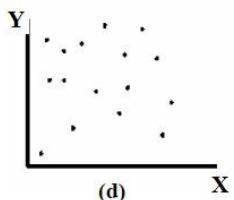

Şekil 9. Değişkenler arasındaki ilişkiler, (a) doğru yönlü, (b) ters yönlü, (c) Doğrusal olmayan, (d) ilişkisiz.

Literatürden, benzetim çalışmalarından ve uygulamadan görüldüğü üzere kılıf gerilimi üzerinde hat uzunluğu (L), kılıf toprak geçiş direnci (Rg), hat akımları (Ia, Ib, Ic), sıfır bileşen akımı (Is) ve gerilimi (Vs), hat başı toplam akım harmoniği bozunumu (THBIb), hat sonu toplam akım harmoniği bozunumunun (THBIs) etkin olduğu görülmüştür. PSCAD/EMTDC benzetim programında, farklı hatlar için Ia, Ib, Ic, Is, Vs, THBIb, THBIs, L ve Rg parametre değerlerine göre benzetim yapılmış ve bu hatlara ait kıllf gerilimleri (Vk) ölçülmüştür. Tahmin yöntemlerinin eğitim çalışmalarında Ia, Ib, Ic, Is, Vs, THBIb, THBIs, L ve Rg parametreleri giriş verileri ve bu parametre değerlerine göre PSCAD/EMTDC benzetim programında ölçülen Vk değerleri de çıkış verileri olarak kullanılmıştır. Tahmin yöntemlerinin eğitiminde kullanılan giriş ve çıkış verilerinin bulunduğu matrisler Şekil 10’da gösterilmiştir.

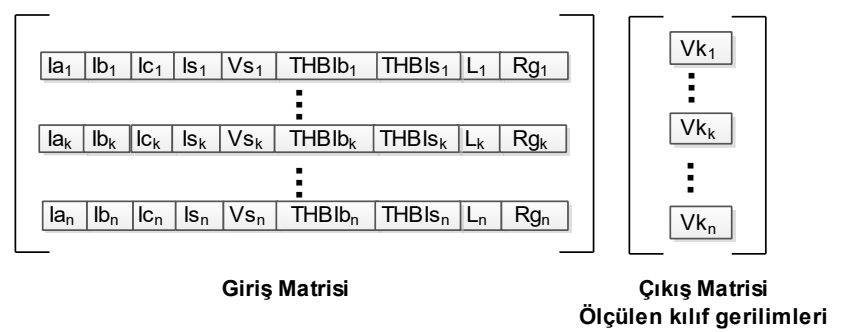

Şekil 10. Eğitimde kullanılan giriş ve çıkış matrisleri

Tahmin yöntemlerinin eğitim işlemleri tamamlandıktan sonra PÇT parametrelerinin optimizasyonu yapılabilir. PÇT yönteminin optimizasyonunda amaç güvenlik ve ekonomikliği sağlayacak en uygun L ve Rg değerlerinin belirlenmesidir. Dolayısıyla bu parametrelerin optimizasyonu için bir giriş matrisi gerekmektedir. Bu giriş matrisi ile hatta oluşabilecek kılıf gerilimi tahmin edilmekte ve tahmin edilen bu kılıf gerilimine göre de optimum L ve Rg değerleri belirlenmektedir. L ve Rg değerleri, belli bir uzunluğa sahip, belli bir yük akımına sahip ve belli bir harmonik bozunumu olan bir hatta ait olacaktır. Dolayısıyla bazı parametreler değişmezken L ve Rg değerleri değişecektir. Şekil 11'de PÇT parametre optimizasyonunda kullanılacak giriş matrisinin nasıl oluşturulduğu özetlenmektedir.

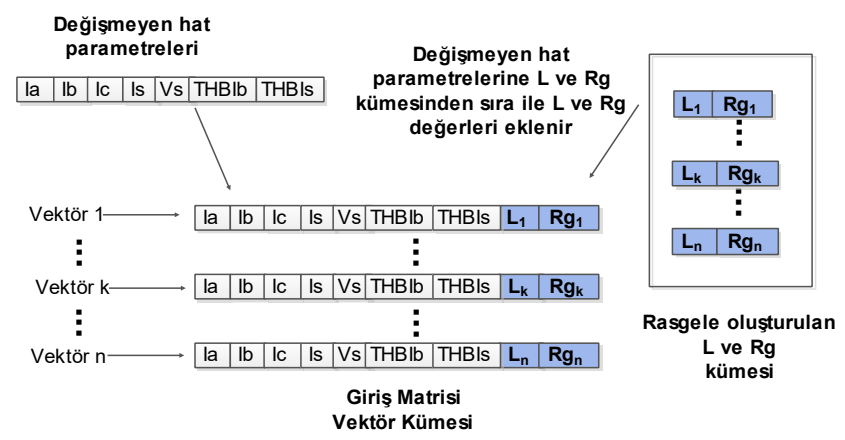

Şekil 11. Giriş Matrisi Oluşturma

Kılıf geriliminin tahmininde kullanılacak giriș matrisinin her bir elemanı bir vektör olarak tanımlanmıștır. Bir vektör olușturulurken Ia, Ib, Ic, Is, Vs, THBIb ve THBIs parametreleri de belli olduğu için bu veriler sabit tutulmuş, değişik L ve Rg parametre değerleri ile giriş matrisinin vektörleri oluşturulmuştur.

PÇT parametreleri optimizasyonunda güvenlik ve ekonomiklik temel ölçütlerdir ve optimizasyon algoritması da buna göre şekillenmiştir. Güvenlik denilince akla en önce insan sağlığı gelmektedir. Elektrik Tesislerinde Topraklamalar Yönetmeliğine göre alternatif akımda dokunma geriliminin sınır değeri $50 \mathrm{~V}$ (etkin değer) olarak belirlenmiştir. Dolayısıyla PÇT parametre optimizasyonunda $50 \mathrm{~V}$ kılıf gerilimi sınır olarak belirlenmiştir. Yani PÇT yönteminde parça uzunluğu belilenirken parça üzerindeki gerilimin $50 \mathrm{~V}$ seviyesini geçmemesi amaçlanır. Diğer bir ölçüt ise ekonomikliktir. Yani PÇT yönteminde parça sayısı ne kadar az olursa yapılan topraklama maliyeti de o denli az olacaktır. Dolayısıyla parça uzunluğu olan L değeri de dokunma gerilimine en yakın değerde olacak şekilde belirlenir. Yani parça uzunluğu belirlenirken, eğitimi tamamlanmış tahmin yöntemi ile tahmin edilen kılıf gerilimi dokunma gerilimine ne kadar yakın değerde ise parça uzunluğu da o denli en yüksek değerdedir. Böylece parça uzunluğu 
olan L en yüksek değerinde ve parça sayısı da en düşük değerinde olacaktır. Böylece hem güvenlik hem de ekonomiklik sağlanacaktır. PÇT parametre optimizasyonu Şekil 12'de gösterilen algoritma ile yapılır.

$\mathrm{L}$ ve Rg kümesini güncelleme işleminde, $\mathrm{L}$ ve Rg değerleri kendileri için belirlenen sinır değerler içinde yeni değerler alırlar. Bu yeni değerlerin belirlenmesinde $\mathrm{L}$ ve Rg parametrelerinin ait oldukları vektör için tahmin edilen kılıf gerilimi kullanılır. Kılıf gerilimi değeri iyi olan vektörlerdeki L ve Rg değerlerinde çok değişiklik yapılmazken, kıllıf gerilimi değerleri iyi olmayan vektörler de büyük değişiklikler yapılır.

Her iterasyon sonunda bir tane iyi vektör seçilerek iyi vektör kümesi maksimum iterasyon sonunda tamamlanır. Belirlenen iterasyon sayısı tamamlandıktan sonra iyi vektörler kümesindeki vektörler kılıf gerilimlerine göre sıralanırlar. İyi vektörler kümesi içinde kılıf gerilimi dokunma gerilimine en yakın olan vektör en iyi vektör olarak seçilir. Seçilen en iyi vektördeki $\mathrm{L}$ ve $\mathrm{Rg}$ değerleri PÇT yöntemi için en uygun değerlerdir.

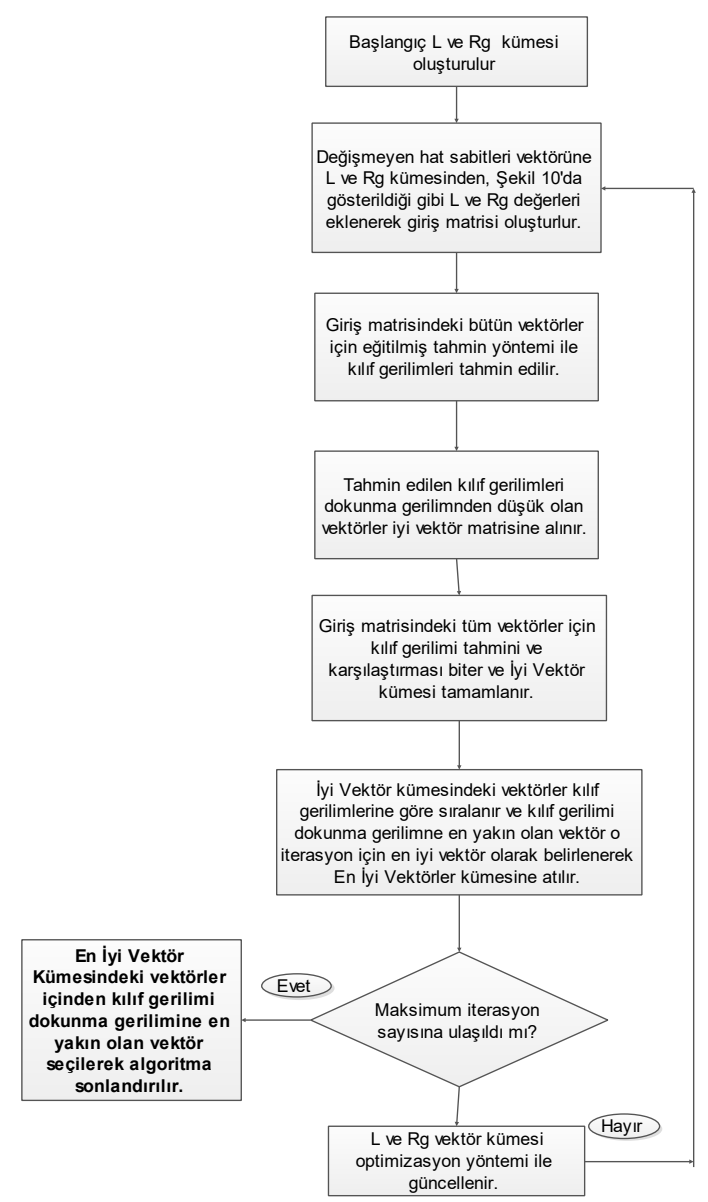

Şekil 12. PÇT optimizasyon algoritması

\section{Bulgular}

$\mathrm{Bu}$ çalışmada hat gerimi $31,5 \mathrm{kV}$, toplam uzunluğu $1000 \mathrm{~m}$, faz akımları $443 \mathrm{~A}, 492 \mathrm{~A}$ ve $367 \mathrm{~A}$ ve $1 \mathrm{x} 240 \mathrm{~mm}^{2}$ kesitli XLPE yalıtkanlı yüksek gerilim kablosuna sahip bir yüksek gerilim hattı için PÇT yöntemi ile kablo topraklaması projelendirilmiştir. PÇT parametrelerinin optimizasyonunda tahmin yöntemleri olarak İleri Beslemeli YSA (IYSA), Layer Recurrent YSA (LRYSA), NARX YSA (NARXYSA), Genetik Algoritma ile yapılan melez YSA (GA-YSA), Doğrusal Regresyon (DR), Tree Regresyon (TR) ve SVM Regresyon (SVMR) yöntemleri kullanılmıştır. Bu yöntemler öncelikle bir veri seti ile eğitilmiştir. Eğitim işlemi için 52x11 boyutunda bir veri seti kullanılmıştır. Bu veri setini oluşturmada 52 ayrı yüksek gerilim kablolu hattın benzetimi PSCAD/EMTDC programında yapılmıştır. Daha sonra bu eğitilmiş yöntemler ile yüksek gerilim kablosunun metal kılıfı üzerinde oluşacak olan kılıf gerilimi tahmin edilmiştir. Tahmin edilen kılıf gerilimine göre de en uygun L ve Rg değerleri belirlenmiştir. Bunların optimizasyonu için de Genetik Algoritma kullanılmıştır.

$\mathrm{Bu}$ yöntemler ile ayrı ayrı L ve Rg değerleri belirlenmiş ve belirlenen değerler PSCAD/EMTDC programında kurulan yüksek gerilim hattı için uygulanmıştır. Algoritma sonucunda tahmin edilen gerilim ile PSCAD/EMTDC programında ölçülen gerilimler karşılaştırılmıştır. 
Tablo 1. Yöntemlerin Karşılaştırılması

\begin{tabular}{c|c|c|c|c}
\hline Yöntem & $\begin{array}{c}\mathbf{L} \\
(\mathbf{m})\end{array}$ & $\begin{array}{c}\mathbf{R g} \\
(\mathbf{o h m})\end{array}$ & $\begin{array}{c}\text { Tahmin } \\
\text { edilen Vk } \\
(\mathbf{V})\end{array}$ & $\begin{array}{c}\text { PSCAD } \\
\text { ölçülen } \\
\text { Vk (V) }\end{array}$ \\
\hline IYYSA & 211 & 27,83 & 40 & 37,44 \\
\hline LRYSA & 233 & 14,10 & 58 & 48 \\
\hline NARXYSA & 147 & 18,17 & 69 & 31 \\
\hline GA-YSA & 337 & 11,85 & 59,59 & 59,13 \\
\hline DR & 242 & 45,93 & 69,07 & 42,92 \\
\hline TR & 253 & 46,8 & 70 & 49 \\
\hline SVMR & 234 & 16,1 & 68,78 & 48 \\
\hline
\end{tabular}

Tablo 1'de L ve Rg parametrelerinin optimum değerleri yöntemlere göre verilmiştir. Tabloda verilen değerlere göre algoritmada tahmin edilen değerler "Tahmin edilen Vk" ile bu değerlerin PSCAD/EMTDC programında yerine konularak benzetimi yapıldığında ölçülen değer ise "PSCAD ölçülen Vk" ile verilmiş̧tir.

\section{Sonuç}

Yüksek tahmin doğruluğuna sahip bir tahmin yönteminin amaç fonksiyonu olarak kullanıldığı bir PÇT optimizasyonunda, güvenlik ve ekonomiklik bakımından en uygun parametreler belirlenir. Tablo 1'de gösterilen tahmin yöntemleri ile yapılan optimizasyon sonunda elde edilen L ve Rg değerleri PSCAD/EMTDC programındaki devrede yerine konmuş ve kılıf gerilimi ölçülmüştür. Tahmin yönteminin kılıf gerilimi ile ölçülen gerilim arasındaki fark en az olan GA-YSA yöntemi olan melez YSA yöntemidir ve doğruluk oranı da \%99 civarındadır. Yani GA-YSA yönteminin amaç fonksiyonu olarak kullanılan bir PÇT optimizasyonunda başarı oranı daha yüksek olacaktır. Böylece elektrik tesislerinde hem can ve mal güvenliği hem de ekonomiklik sağlanmış olacaktır.

\section{Kaynakça}

C. L. Bak and F. F. Silva, "High voltage AC underground cable systems for power transmission - A review of the Danish experience, part 1." Electric Power Systems Research, vol. 140, pp. 984-994, 2016.

A. D. Tziouvaras, "Protection of high-voltage AC cables", in Proc. 59th Annual Conf. for Protective Relay Engineers, 2006, TX, USA, p. 48-61.

K. G. Sachin, P. Arun, , "Study on Semi Conductive Layer during EHV XLPE Cable Joint Procedure" International Journal of Novel Research in Engineering and Science, vol. 3, pp. 8-11, 2016.

S. Czapp, K. Dobrzynski, J. Klucznik, "Calculation of induced sheath voltages in power cables - single circuit system versus double circuit system" Journal of Information, Control and Management Systems, vol. 12, pp. 113-123, 2014.

K. V. Gouramanis, C. G. Kaloudas, T. A. Papadopoulos, "Sheath voltage calculations in long medium voltage power cables," in Proc.IEEE Trondheim Power Tech, 2011,Norway, pp. 1-7

C. K. Jung, J. B. Lee and J. W. Kang, "Sheath circulating current analysis of a cross-bonded power cable systems" J Electr Eng \& Technol, vol. 2, pp. 320-328, 2007.

J. R. Ruiz, A. Garcia and X. A. Morera,. "Circulating sheath currents in flat formation underground power lines." In Proc. 2007 International Conf. Renewable Energies and Power Quality, March 2007, pp. 1-5.

C. K.Jung, J. B. Lee and J. W. Kang, "Sheath current characteristic and its reduction on underground power cable systems" IEEE Power Engineering Society General Meeting, CA, USA, 2005, pp. 2562-2569

D. Xiang, Y. Yang, Z. Chengke and M. H. Donald, "Online Monitoring and Diagnosis of HV Cable Faults by Sheath System Currents", IEEE Transactions On Power Delivery, vol. 32, pp. 2281-2290, 2017.

Z. Shuai, G. Houlei and S. Yingtao. "A New Fault-Location Algorithm for Extra-High-Voltage Mixed Lines Based on Phase Characteristics of the Hyperbolic Tangent Function.” IEEE Transactions on Power Delivery, vol. 31, pp. 1203-1212, 2016.

L. Bessissa, L. Boukezzi, D. Mahi,. "Influence of Fuzzy Parameters on the Modeling Quality of XLPE Insulation Properties under Thermal Aging." Fuzzy Information and Engineering, vol. 8, pp. 101-112, 2016.

B. Yunus, "Trend adjusted lifetime monitoring of underground power cable". Electric Power Systems Research, vol. 143, pp. 189-196, 2016.

L. Zhonglei, X. B. Du and L. Wang, "The calculation of circulating current for the single-core cables in smart grid", in Proc. 2012 IEEE Innovative Smart Grid Technologies - Asia, China, May 2012, pp. 1-4.

Q. Jiangchao and S. Maryam, "A Zero-Sequence Voltage Injection-Based Control Strategy for a Parallel Hybrid Modular Multilevel HVDC Converter System”, IEEE Transactions on Power Delivery, vol. 30, pp. 728 - 736, 2015.

N. Mehdi, M. Gerry, "Three-Phase Multi module VSIs Using SHE-PWM to Reduce Zero-Sequence Circulating Current", IEEE Transactions on Industrial Electronics, vol. 61, pp. 1659 - 1668, 2014.

B. Akbal, "Applications of artificial intelligence and hybrid neural network methods with new bonding method to prevent electroshock risk and insulation faults in high-voltage underground cable lines", Neural Comput \& Applic, vol. 24, pp. 32-36, 2018.

Ö. Otkun, R. Ö. Doğan and A. S. Akpınar, "Doğrusal Hareketli Sürekli Mıknatıslı Senkron Motorun Yapay Sinir Ağ Tabanlı Skaler Hiz Denetimi”, Gazi Üniv. Müh. Mim. Fak. Der., vol. 30, pp. 395-404, 2015.

A. Kayabaşi and A. Akdağli, "Oyuk Yüklü Kompakt Mikroşerit Antenlerin Rezonans Frekansının Hesaplanmasında YSA ve BMSDUA Yöntemlerinin Kullanımı”, Gazi Üniv. Müh. Mim. Fak. Der., vol. 31, pp. 105-117, 2016.

S. Şahinler, "En Küçük Kareler Yöntemi ile Doğrusal Regresyon Modeli Oluşturmanın Temel Prensipleri." MKÜ Ziraat Fakültesi Dergisi, vol. 5, pp. 57-73, 2000. 